\title{
Damage to the Lateral and Central, but Not Other, Amygdaloid Nuclei Prevents the Acquisition of Auditory Fear Conditioning
}

\author{
Karim Nader, Pedram Majidishad, Prin Amorapanth, and Joseph E. LeDoux ${ }^{1}$ \\ W.M. Keck Foundation Laboratory for Neurobiology, Center for Neural Science, New York University, New York, New York 10003, USA
}

\begin{abstract}
It is well established that the amygdala plays an essential role in Pavlovian fear conditioning, with the lateral nucleus serving as the interface with sensory systems that transmit the conditioned stimulus and the central nucleus as the link with motor regions that control conditioned fear responses. The lateral nucleus connects with the central nucleus directly and by way of several other amygdala regions, including the basal, accessory basal, and medial nuclei. To determine which of these regions is necessary, and thus whether conditioning requires the direct or one of the indirect intra-amygdala pathways, we made lesions in rats of the lateral, central, basal, accessory basal, and medial nuclei, as well as combined lesions of the basal and accessory basal nuclei and of the entire amygdala. Animals subsequently underwent fear conditioning trials in which an auditory conditioned stimulus was paired with a footshock unconditioned stimulus. Animals that received lesions of the lateral or central nucleus, or of the entire amygdala, were dramatically impaired, whereas the other lesions had little effect. These findings show that only the lateral and central nuclei are necessary for the acquisition of conditioned fear response to an auditory conditioned stimulus.
\end{abstract}

The neural circuits underlying Pavlovian fear conditioning are believed to involve transmission of the conditioned stimulus (CS) to the lateral nucleus of the amygdala (LA) and the control of conditioned fear responses by way of projections from the central nucleus of the amygdala (CE) to brainstem areas (see Maren and Fanselow 1996; Davis and Lee 1998; Fendt and Fanselow 1999; LeDoux 2000). Given that the LA projects directly to the CE (Paré et al. 1995; Pitkänen et al. 1997), it is possible that these two nuclei and the connections between them fully account for the amygdala's role in fear conditioning. However, there are several other routes within the amygdala through which processing in LA could reach CE.

For example, LA projects to the basal (B), accessory basal (AB), and medial (M) nuclei, each of which projects to CE (Pitkänen et al. 1997). Although damage to either the LA (LeDoux et al. 1990a; Amorapanth et al. 2000) or the CE (Kapp et al. 1979; LeDoux et al. 1986; Hitchcock and Davis 1991; Roozendaal et al. 1991b; Rosen et al. 1991; Maisonnette et al. 1996) prevents fear conditioning, relatively little is known about the effects of damage restricted to $\mathrm{B}, \mathrm{AB}$, and $M$. Numerous studies have made relatively large lesions of the so-called basolateral complex, which includes LA and $\mathrm{B}$, and sometimes $\mathrm{AB}$, and blocked the acquisition of fear conditioning (e.g., Sananes and Davis 1992; Campeau and

${ }^{1}$ Corresponding author.

E-MAIL ledoux@cns.nyu.edu; FAX (212) 995-4704.

Article and publication are at www.learnmem.org/cgi/doi/10.1101/ $\operatorname{lm} .38101$.
Davis 1995; Maren et al. 1996). However, because damage to LA alone disrupts conditioning, it is not possible to draw conclusions about the role of the $\mathrm{B}$ or $\mathrm{AB}$ from such studies. Damage restricted to $\mathrm{B}$ was found to have no effect in one previous study (Amorapanth et al. 2000), but the effects of damage to $\mathrm{AB}$ and $\mathrm{M}$ alone have not been assessed.

The goal of the present study was to re-examine the contribution of amygdala areas to fear conditioning by placing discrete lesions in several of the major nuclear regions, especially those that might serve as links between sensory processing of the CS and control of the expression of the conditioned responses. A standard auditory fear conditioning task was used in which a tone CS was paired with a footshock unconditioned stimulus (US). Lesions were made bilaterally in the $\mathrm{LA}, \mathrm{CE}, \mathrm{B}, \mathrm{AB}$, or $\mathrm{M}$. Additional groups received combined lesions of $B$ and $A B$. Further, a group sustaining large bilateral lesions that essentially destroyed the entire amygdala was also included to determine the maximal effects of amygdala damage. Control subjects either received sham operations or were not operated on. A separate group of controls was given unpaired training to determine the extent to which the association formed between the CS and US accounts for conditioning in the groups given paired training.

\section{RESULTS}

\section{Histology}

For all structures targeted, animals were only included in the statistical analysis if vast majority of the structure of interest was destroyed bilaterally with minimal infringe-

LEARNING \& MEMORY 8:156-163 @ 2001 by Cold Spring Harbor Laboratory Press ISSN1072-0502/01 \$5.00

$$
\begin{array}{lllllllllllllll}
L & E & A & R & N & I & N & G & \mathbf{Q} & M & E & M & O & R & Y \\
\text { www.learnmem.org } & & & &
\end{array}
$$


ment on neighboring nuclei. Extent of damage was estimated from histological sections. The residual tissue typically consisted of either the rostral or caudal areas of the nucleus (Figs. 1, 2).

\section{Entire Amygdala}

Of the seven animals that received large amygdala lesions, three were excluded from the statistical analysis due to sparing of significant amounts of the amygdala. The remaining four animals sustained massive damage that included all amygdala nuclei. In addition, the overlying caudate/putamen and pyriform cortex, ventrally were typically damaged.

$L A$

The LA was targeted in 45 animals. Of these, six were included in the statistical analysis. Acceptable lesions de-
$-2.3$

Entire Amygdala

Lateral Nucleus

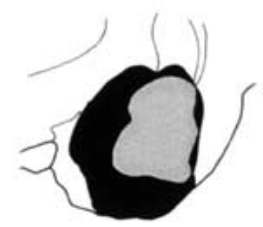

Central Nucleus

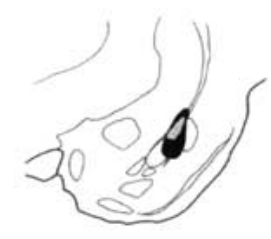

Basal Nucleus

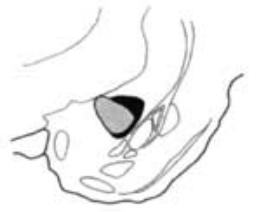

Accessory Basal Nucleus

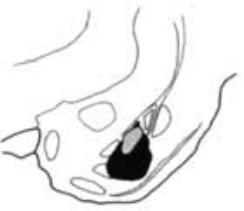

Basal \& Accessory Basal Nucleus

Medial Nucleus

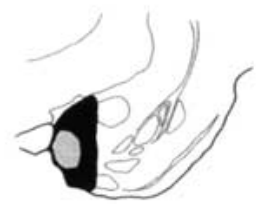

$-3.1$
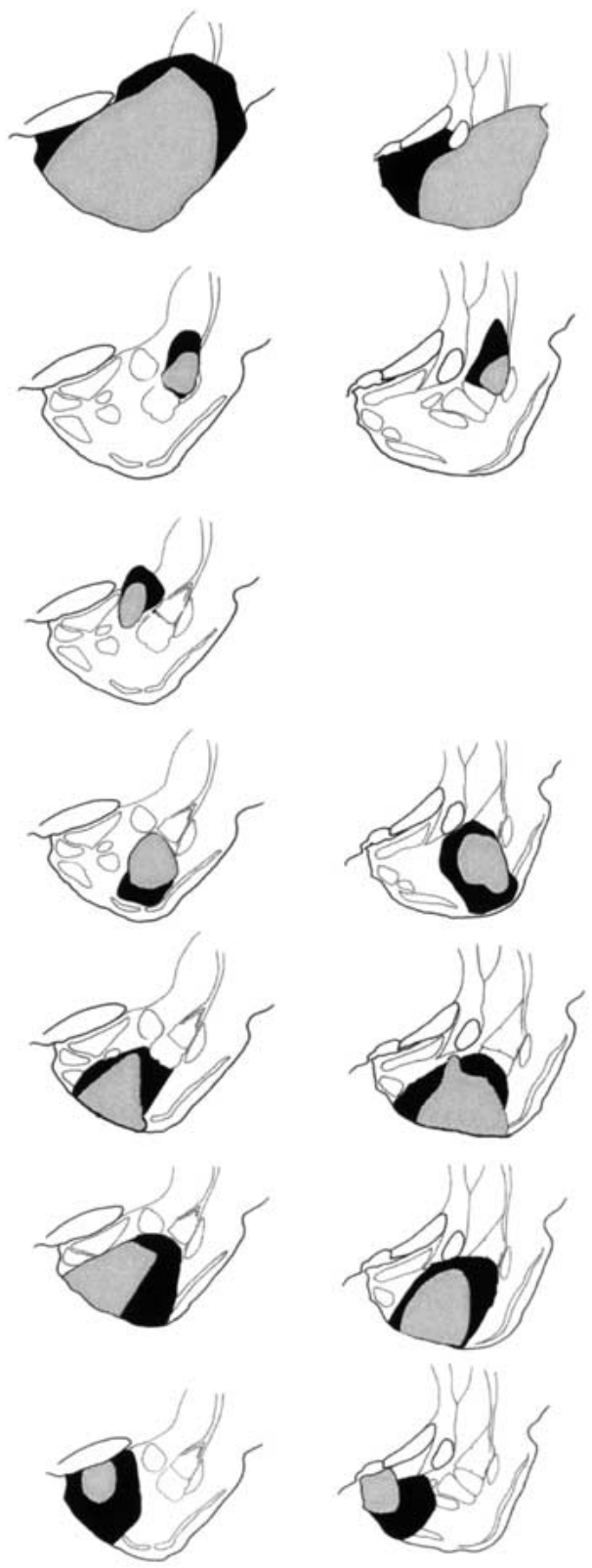

Figure 1 Camera Lucida drawings of the various surgical groups. The shadings show the smallest and largest extent of the damage a structure sustained for animals included in the statistical analysis. The numbers in bold indicate the approximate distance posterior to bregma that a section represents.

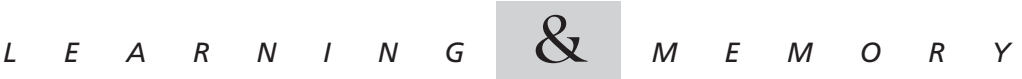

$$
\begin{aligned}
& \text { www.learnmem.org }
\end{aligned}
$$


Sham Lesion

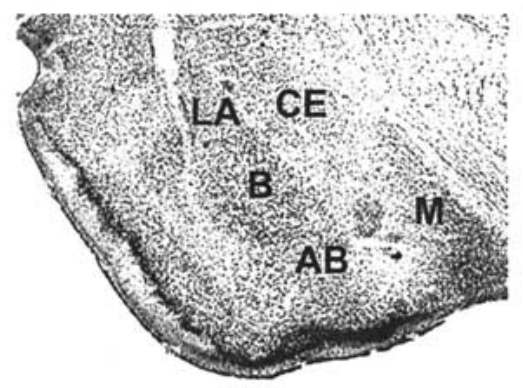

Central Nucleus Lesion

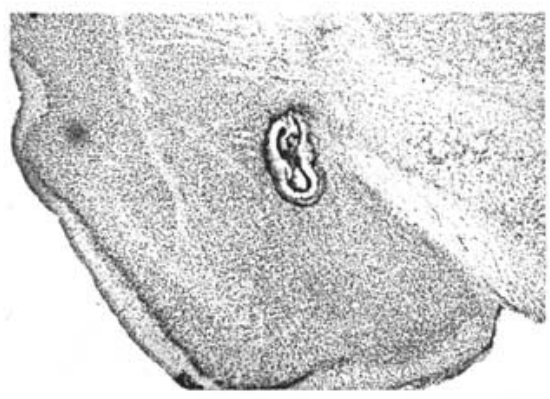

\section{Lateral Nucleus Lesion}

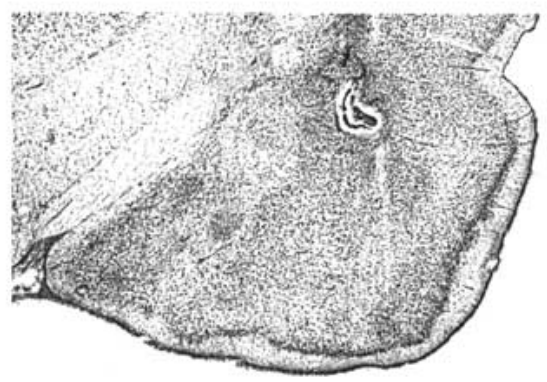

Basal Nucleus Lesion

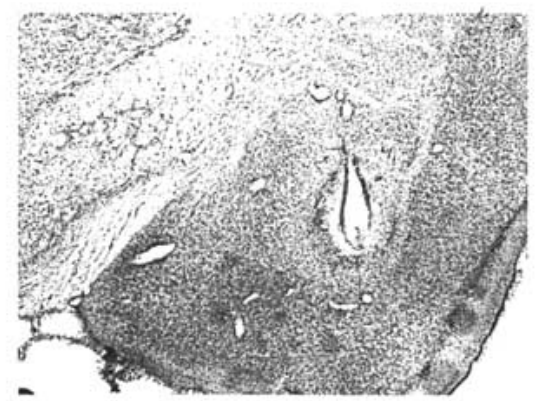

\section{Accessory Basal Nucleus Lesion}

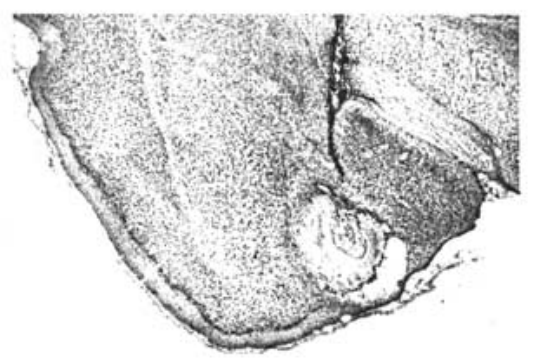

Medial Nucleus Lesion

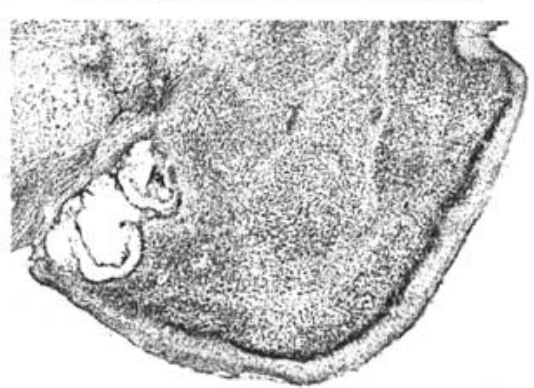

Figure 2 Composite photographs showing complete lesions of a structure. All images are unilateral.

stroyed much of the LA and minimally infringed on the CE or the B. Although the dorsal division of the LA was always damaged, there was variable damage to the ventral regions.

\section{CE}

Twenty rats received lesions of the CE. Of these, 15 were excluded due to excessive sparing of tissue or because the lesions infringed on adjacent amygdala nuclei. The remaining five rats had extensive damage restricted to CE bilaterally along the rostro-caudal extent.

B

Of 25 rats that received lesions targeted at the $\mathrm{B}, 8$ were included in the statistical analysis. Tissue damage spared the
CE but in some cases infringed on the ventral portion of the ventral LA. Furthermore, caudally damage extended to the anterior cortical nucleus, periamygdaloid, and pyriform cortex. Portions of the accessory nucleus were also damaged.

\section{$A B$}

Of 40 rats that were lesioned, 12 were included in the statistical analysis. In addition to the $\mathrm{AB}$, the periamygdala and pyriform cortex were consistently damaged. Dorsally, portions of the ventral $B$ were occasionally damaged.

\section{$B+A B$}

Twenty rats received lesions targeted at the $\mathrm{B}+\mathrm{AB}$. Of these, six were included in the statistical analysis.

\section{M}

The medial nucleus was significantly destroyed bilaterally in 9 out of 20 rats. The lesions also damaged the periamygdaloid cortex. Caudally, the amygdalo-hippocampal area and posterior cortical area were also partially damaged.

\section{Behavioral Results}

Approximately $24 \mathrm{~h}$ after being conditioned, all animals were placed in a novel chamber. They were then exposed to the auditory $\mathrm{CS}$ for $60 \mathrm{sec}$. The amount of freezing exhibited during the CS and in the time immediately prior to the onset of the CS (pre-CS period) was measured. As shown in Figure 3, little freezing occurred in the pre-CS period in any of the groups. In the unoperated and sham operated controls given paired training, much of the $60 \mathrm{sec}$ test was accounted for by freezing. In contrast, little freezing was observed in a group of unoperated animals given unpaired training (in which the CS and US did not overlap). The dramatic difference between the paired and unpaired groups indicates that freezing to the CS in the paired group is due to the specific association of CS with the US and is not a nonassociative consequence of presenting the CS and US during training.

All lesioned groups received paired training. Freezing during the CS was greatly reduced, relative to the controls,

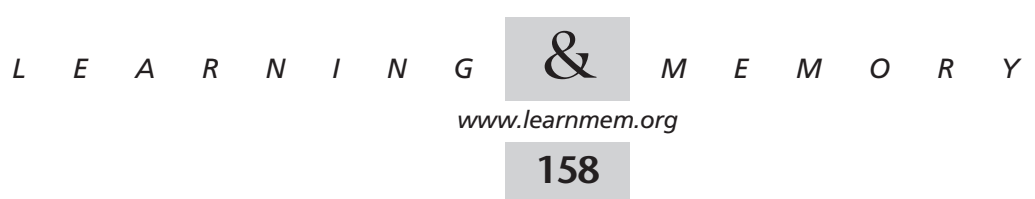




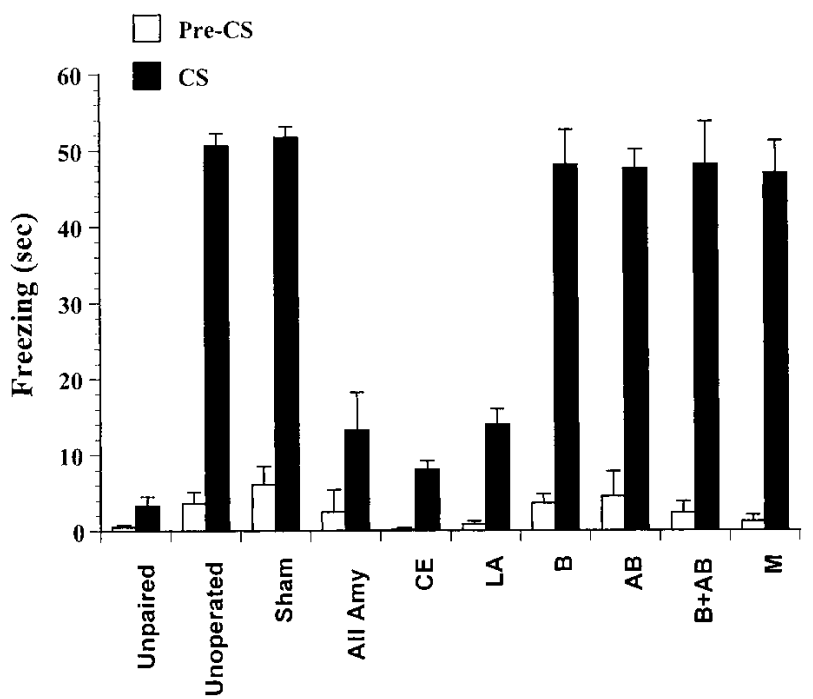

Figure 3 The effects of pretraining lesions on the acquisition of conditioned freezing behavior elicited by a Tone. All Amy, entire amygdala; $C E$, central nucleus; $L A$, lateral nucleus; $B$, basal nucleus; $A B$, accessory basal nucleus; $B+A B$, basal and accessory basal nuclei; $M$, medial nucleus; $C P$, caudate/putamen. Bars represent group means + SEM.

in the groups with large amygdala lesions or with lesions of the $\mathrm{LA}$ or $\mathrm{CE}$. Damage to $\mathrm{B}, \mathrm{AB}, \mathrm{M}$, or $\mathrm{B}+\mathrm{AB}$ had no observable effect. The freezing scores were statistically evaluated using a repeated measures analysis of variance
(ANOVA) that compared the amount of freezing across groups in the two sampling periods (pre-CS and CS; Fig. 1). The main effects of group $(F[10,91]=26, P<0.05)$ and sampling period $(F[1,91]=760, P<0.05)$ were significant, as was the interaction between these factors $(F[10$, $91]=24, \quad P<0.05)$. Post-hoc Newman-Keuls tests, with groups and sampling period as factors were performed. There was no difference in freezing between any of the groups during the pre-CS time $(P s>0.05)$. However, the groups differed in the amount of freezing exhibited during the CS (for summary, see Table 1). Sham and unoperated controls given paired training froze significantly more than unoperated controls given unpaired training, further supporting the view that CS-elicited freezing is an associatively conditioned response. The large-amygdala-lesion group, and the groups with LA and CE lesions froze significantly less than both the unoperated controls or sham groups $(P \mathrm{~s}<$ 0.05), and at comparable levels to each other and to unpaired controls. In contrast, all the other groups froze significantly more than the unpaired group. $\mathrm{B}, \mathrm{AB}, \mathrm{B}+\mathrm{AB}$, and $M$ were not different from the unoperated or sham groups.

\section{DISCUSSION}

To determine which amygdala nuclei are necessary for the acquisition of conditioned fear responses (freezing) to auditory stimuli, we made lesions of either the entire amygdala, or of specific amygdala nuclei, including the LA, B, CE, $\mathrm{AB}$, and $\mathrm{B}$ combined with $\mathrm{AB}$ or $\mathrm{M}$. These areas were chosen

Table 1. Freezing Exhibited During Conditioned Stimulus

\begin{tabular}{|c|c|c|c|c|c|c|c|c|c|c|c|}
\hline & Unpaired & & & & & & & & & & \\
\hline Unoperated & $*$ & Unoperated & & & & & & & & & \\
\hline Sham & $*$ & NS & Sham & & & & & & & & \\
\hline Amygdala & NS & * & * & Amyg. & & & & & & & \\
\hline CE & NS & * & * & NS & $\mathrm{CE}$ & & & & & & \\
\hline LA & NS & * & * & NS & NS & LA & & & & & \\
\hline B & * & NS & NS & * & * & * & B & & & & \\
\hline$A B$ & * & NS & NS & * & * & * & NS & $A B$ & & & \\
\hline$B+A B$ & * & NS & NS & * & * & $*$ & NS & NS & $\mathrm{B}+\mathrm{AB}$ & & \\
\hline M & * & NS & NS & * & * & * & NS & NS & NS & M & \\
\hline $\mathrm{CP}$ & * & NS & * & * & * & * & NS & NS & NS & NS & $\mathrm{CP}$ \\
\hline Means & 3.29 & 50.69 & 51.96 & 13.25 & 8.0 & 14.0 & 48.13 & 46.83 & 48.17 & 47.00 & 38.40 \\
\hline
\end{tabular}

NS, not significant.

*, PL, OS

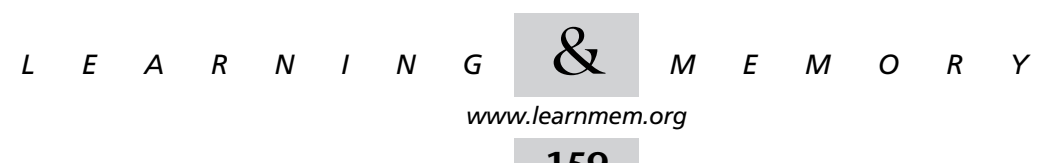


because each is a potential link between sensory and motor processing within the amygdala (see above).

Large lesions of the amygdala blocked fear conditioning, as has long been known (e.g., Blanchard and Blanchard 1972). A similar degree of impairment was produced by lesions restricted to LA or CE. The amount of freezing during the CS in these groups was in fact no different from that in the unpaired group, which received nonassociative training. In contrast, groups with damage to $\mathrm{B}, \mathrm{AB}, \mathrm{B}+\mathrm{AB}$ or $\mathrm{M}$ were significantly different from the unpaired group but not from the unoperated and sham-operated groups receiving paired training.

These findings are consistent with previous studies showing that damage to LA and CE disrupts conditioned fear responses (Kapp et al. 1979; LeDoux et al. 1988, 1990a; Roozendaal et al. 1991a; Sananes and Davis 1992; Campeau and Davis 1995; Oakes and Coover 1997; Poremba and Gabriel 1997; Walker and Davis 1997). The fact that damage to $\mathrm{B}, \mathrm{AB}, \mathrm{B}$, and $\mathrm{AB}$ together or $\mathrm{M}$ fail to interfere with fear conditioning strongly suggests that LA and CE are sufficient on their own. Two interpretations follow from these findings. First, the direct connections from LA to CE, rather than indirect pathways involving the other nuclei, are necessary for fear conditioning. Second, information from the LA can use redundant indirect routes to the $\mathrm{CE}$ to engage the freezing response. For example, the B may normally link the LA and CE. However, in its absence, projections from the LA to the CE may substitute.

Although the connections from LA to $\mathrm{B}, \mathrm{AB}$ and $\mathrm{M}$, and from these nuclei to $\mathrm{CE}$ are not necessary for conditioning to occur, these may nevertheless participate in the intact brain. To test this possibility it would be necessary to selectively disrupt the pathway from LA to CE and then test the role of these regions. Such an experiment is difficult given techniques currently available.

The failure of a lesion to disrupt fear conditioning shows that the region is not necessary for the particular fear conditioning task but does not necessarily mean that the region has no role in fear learning. For example, once an auditory stimulus acquires aversive properties through fear conditioning, it can then motivate the learning of active responses that allow escape or avoidance from threatening situations by serving as a conditioned reinforcer (Mowrer and Lamoreaux 1946; Miller 1948; McAllister and McAllister 1971). Although lesions of B have no effect on fear conditioning to an auditory CS, lesions of LA and B either alone (Amorapanth et al. 2000) or together (Killcross et al. 1997) prevent instrumental learning motivated by an auditory CS (however, it has been reported for a different task that there is no correlation between damage to the $\mathrm{B}$ and the ability of rabbits to acquire an active avoidance response; Poremba and Gabriel 1997). Lesions of the CE, but not B, prevent the acquisition of freezing behavior elicited by auditory fear conditioning. Conversely, lesions of the $\mathrm{B}$, but not $\mathrm{CE}$, block the instrumental learning as measured using an escape-fromfear task (Amorapanth et al. 2000). This double dissociation shows there are two output systems for the amygdala. The $\mathrm{CE}$ mediates reactive, reflexive fear responses and the $\mathrm{B}$ mediates the conditioned reinforcement that will drive the acquisition of active fear responses (Killcross et al. 1997; Amorapanth et al. 2000). Only lesions of the LA block the acquisition of both responses, suggesting that it is the site of plasticity for fear learning and the B and CE separate outputs (Amorapanth et al. 2000). Thus, the reasons why lesions of the LA and CE block fear condition are different. Lesions of the LA block fear conditioning because this is the site of plasticity mediating the learning. Lesions of the CE block fear conditioning because this is the motor output through which learned information needs to access the circuits controlling freezing.

The question arises as to whether the lesions that had no effect were sufficiently complete to rule out a role in fear conditioning. The lesions of B in this study were similar to ones in our conditioned reinforcement study. Because the lesions were effective in disrupting instrumental learning in that study, we have an independent indication that lesions of that size can be effective. In the case of the other lesions, there is no independent behavioral evidence that allows us to judge the effectiveness of the lesions and we are left to base our conclusions on the fact that our histological observations indicate that the regions sustained extensive damage.

We used electrolytic lesions because these can be restricted to small regions of the amygdala with minimal infringement onto neighboring structures. However, electrolytic lesions can interrupt functions mediated by pathways passing through the lesion, as well as the functions mediated by the area destroyed. For this reason, positive effects of lesions must be carefully interpreted (e.g., Dunn and Everitt 1988). Given the pattern of the present results, together with previously published findings showing that fiber-sparing neurotoxic lesions of the LA and B together disrupt fear conditioning (e.g., Sananes and Davis 1992; Maren et al. 1996), it is unlikely that damage to fibers passing through the amygdala accounts for our results. Further, functional inactivation of LA and B disrupts fear conditioning (Helmstetter and Bellgowan 1994; Muller et al. 1997; Wilensky et al. 2000). Because electrolytic lesions of LA but not $\mathrm{B}$ disrupt conditioning, the effects of LA + B neurotoxic lesions or $\mathrm{LA}+\mathrm{B}$ inactivation are likely to be due to actions in LA. Similarly, since neurotoxic lesions of CE disrupt conditioned fear responses (Killcross et al. 1997), the effects of electrolytic lesions in the present study are likely to be due to a disruption of functions localized to $\mathrm{CE}$ rather than to functions mediated by fibers passing through CE.

Our results are most directly applicable to auditory fear conditioning but may also apply to studies in which other discrete unimodal sensory stimuli are used as a CS since the

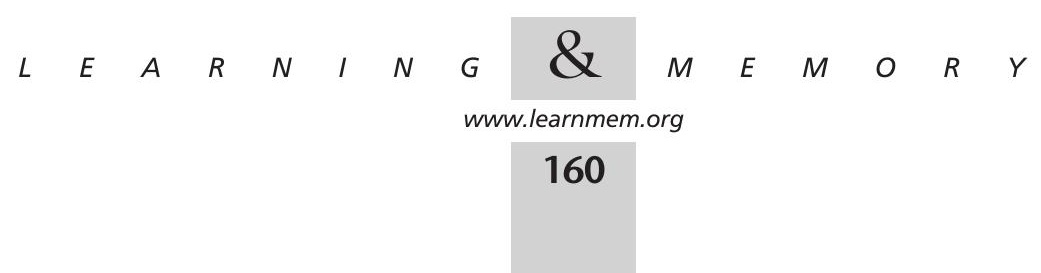


LA is the main link in the amygdala with sensory systems in mammals (LeDoux et al. 1990b; Amaral et al. 1992; Pitkanen et al, 1997; McDonald 1998). In contrast, our findings may not apply to contextual conditioning, which is believed to involve connections from the hippocampus to the amygdala (Phillips and LeDoux 1992; Kim et al. 1993), because the main projections from the hippocampus terminate in the $\mathrm{B}$, $\mathrm{AB}$, and CE (Canteras and Swanson 1992). However, there are some minor projections from hippocampal areas to LA (Stefanacci et al. 1996), and recent studies have shown that portions of LA are functionally activated in response to a contextual CS (Wallace and Rosen 1999). Nevertheless, additional studies are needed to clarify the role of amygdala regions in contextual conditioning. Particularly important will be the use of tasks in which conditioning depends on an association involving a representation of the context rather than on tasks in which conditioning to unimodal and contextual stimuli cannot be differentiated (e.g., Phillips and LeDoux 1992; Maren et al. 1997; Frankland et al. 1998).

In summary, we have shown that damage to LA and $\mathrm{CE}-$ but not $\mathrm{B}, \mathrm{AB}$, or $\mathrm{M}$-disrupts the acquisition of conditioned freezing in response to auditory fear conditioning. $\mathrm{LA}$ and CE and the connections between them thus are sufficient to mediate fear conditioning. Future studies involving physiological recordings, perhaps in conjunction with lesions, will be required to determine more precisely how processing within this circuitry allows sensory stimuli to come to control fear reactions as a result of their association with painful or other aversive stimuli.

\section{MATERIALS AND METHODS}

\section{Subjects}

All subjects were adult male Sprague-Dawley rats housed in pairs in Plexiglas cages. All animals weighed between 275 and $300 \mathrm{~g}$ upon arrival at the laboratory and were kept on a 12-h light-dark cycle with lights on at 7:30 A.M. Rats had ad libitum access to food and water for the duration of the experiment. Rats remained in the vivarium undisturbed for $5 \mathrm{~d}$. The animals were then handled each day for $5 \mathrm{~d}$ after the experiments were begun.

\section{Surgery}

Rats were injected with $0.15 \mathrm{cc}$ atropine intraperitoneally (ip), anaesthetized with Nembutal (ip, $0.1 \mathrm{cc} / 100 \mathrm{~g}$ body weight, 50 $\mathrm{mg} / \mathrm{mL}$ ), and placed in a stereotaxic frame. The cranium was exposed and four burr holes were drilled using a dental drill. A stainless steel, monopolar electrode insulated with epoxy to within 200 $\mu \mathrm{m}$ of the tip was lowered through an incision in the dura to the target brain area. Lesions were made by passing positive current of various durations through the electrode at each lesion site. Coordinates taken from for the various experimental groups are given in Table 2 (Paxinos and Watson 1997). Animals in the sham lesion group had identical electrode placements, with the exception that the DV coordinate was 1-1.5 mm dorsal to the experimental group and no current was passed through the electrode.

Following completion of surgery, the wound was closed and the animal was placed in its home cage, which rested under a heat
Table 2. Coordinates Relative to the Skull Surface at Bregma (in Millimeters) and Current Duration

\begin{tabular}{|c|c|c|c|c|}
\hline & Posterior & Medial/Lateral & Ventral & $\begin{array}{l}\text { Duration } \\
\quad \text { (sec) }\end{array}$ \\
\hline Entire & 2.3 & \pm 4.8 & 8.4 & 20 \\
\hline Amygdala & 3.0 & \pm 5.2 & 8.5 & 20 \\
\hline \multirow[t]{3}{*}{ LA } & 2.3 & \pm 5.1 & 8 & 9 \\
\hline & 3.2 & \pm 5.3 & 8.1 & 10 \\
\hline & 4.0 & \pm 5.5 & 8.1 & 11 \\
\hline \multirow[t]{3}{*}{ CE } & 1.8 & \pm 4.4 & 8.4 & 12 \\
\hline & 2.3 & \pm 4.4 & 8.4 & 12 \\
\hline & 2.8 & \pm 4.4 & 8.4 & 12 \\
\hline \multirow[t]{4}{*}{ B } & 2.1 & \pm 4.9 & 9.1 & 12 \\
\hline & 2.8 & \pm 4.9 & 9.3 & 15 \\
\hline & 3.3 & \pm 5.3 & 9.2 & 15 \\
\hline & 4.2 & \pm 5.3 & 9.3 & 15 \\
\hline \multirow[t]{2}{*}{ AB } & 3.1 & \pm 4.8 & 9.8 & 10 \\
\hline & 3.6 & \pm 4.5 & 9.5 & 10 \\
\hline \multirow[t]{4}{*}{$\mathbf{B}+\mathbf{A B}$} & 2.1 & \pm 4.9 & 9.1 & 12 \\
\hline & 3.0 & \pm 4.9 & 9.6 & 18 \\
\hline & 3.5 & \pm 4.9 & 9.4 & 18 \\
\hline & 4.2 & \pm 5.3 & 9.3 & 15 \\
\hline \multirow[t]{3}{*}{$\mathbf{M}$} & 2.3 & \pm 3.2 & 9.0 & 10 \\
\hline & 3.2 & \pm 3.3 & 9.0 & 10 \\
\hline & 3.8 & \pm 3.6 & 9.2 & 12 \\
\hline \multirow[t]{4}{*}{ CP } & 1.8 & \pm 4.9 & 7.5 & 12 \\
\hline & 2.4 & \pm 4.7 & 7.4 & 12 \\
\hline & 3 & \pm 4.9 & 7.4 & 10 \\
\hline & 3.6 & \pm 5.2 & 6.8 & 10 \\
\hline
\end{tabular}

lamp. After recovery from surgery, the animal was returned to the animal housing area and allowed to recover undisturbed for a 1-wk period.

\section{Apparatus}

Prior to each phase of the experiment, animals were transported to a holding room in the vivarium. This room is distinct from the rooms in which conditioning took place. Distinct environments were used for conditioning and testing. All rats received fear conditioning in a conditioning chamber (chamber A, Model E10-10, Coulbourn Instruments) with a metal grid floor. Black plastic inserts with diagonal white lines on them were fitted to the two side and back walls. The front wall was made of clear Plexiglas. A single house light illuminated the chamber. This conditioning chamber was contained within a sound-attenuating cubicle (Model E10-20, Coulbourn). The apparatus was cleaned with an industrial detergent after each use.

Testing took place in four standard operant chambers (ENV001, Med Associates) that were located in a different room in the vivarium (chamber B). The only modification made to these chambers was that the normal metal grid floor was covered with a sheet of white plastic. The plastic floor was wiped before and after each conditioning session with a peppermint-odored soap. These chambers had two levers extending into them. The house light and two key lights produced illumination for the chamber. These chambers were contained within a sound-attenuating cubicle (ENV-022M, Med Associates). A 1.5-in hole was drilled through the top of the cubicle, over which video cameras were mounted and which recorded the animals; behavior.

$$
\begin{array}{lllllllllllllll}
L & E & A & R & N & I & N & G & \mathcal{Q} & M & E & M & O & R & Y \\
\text { www.learnmem.org } & &
\end{array}
$$




\section{General Procedures}

\section{Habituation}

Rats were habituated to chambers A and B over a 2-d period in a counterbalanced order. On the first day, half the rats were placed in chamber A for $20 \mathrm{~min}$ and the remaining rats were placed in chamber B for $20 \mathrm{~min}$. The following day, each rat was habituated to the alternate environment for the same amount of time.

\section{Fear Conditioning}

The training procedure has been described in detail previously (Phillips and LeDoux 1992; Morgan et al. 1993). On the two days following habituation (days 1 and 2), classical-conditioning trials began ( 2 trials per day, 2 d). These trials entailed transporting animals into the training room and placing them individually into chamber A. The CS was a $10-\mathrm{kHz}$ tone and the US a $0.5-\mathrm{sec}(0.5 \mathrm{~mA})$ scrambled shock through the floor grid. For rats receiving paired fear conditioning, the CS was presented for $20 \mathrm{sec}$ through a speaker mounted on the front panel of the chamber. The US coterminated with the CS. The intertrial interval averaged $120 \mathrm{sec}$ with a range between 90-150 sec. Each daily session began $\sim 120 \mathrm{sec}$ after being placed in the box.

Unpaired fear conditioning entailed presenting the CS on the same schedule as the paired procedure. The US, however, was presented pseudo-randomly such that the order of stimulus presentation was US/CS/US/CS, with the US not occurring within $60 \mathrm{sec}$ of CS1 termination.

\section{Test}

On day 3 , the animals were transported and placed into chamber B and allowed to explore. At minute 10 the CS was presented for 60 sec. The number of seconds spent freezing during CS presentation was determined by observing the video tape of the rats' behavior in the chamber. Freezing was defined as immobility, with the exception of respiratory-related movement. The duration of freezing during the CS was compared to the duration of freezing in the 60-sec period just before the onset of the CS (pre-CS period). Freezing was scored by people blind to the experimental groups that the animals belonged to.

\section{Histology}

Following completion of the behavioral studies, animals were deeply anaesthetized with Nembutal $(0.5 \mathrm{cc}, 50 \mathrm{mg} / \mathrm{mL})$ and transcardially perfused with physiological saline and $10 \%$ buffered formalin. The brains were stored in 30\% sucrose in formalin postfix solution and sectioned on a microtome at $50 \mu \mathrm{m}$. Every other section was collected on a slide and stained with cresyl violet. Sections were examined and images digitally captured under bright-field microscopy using Stereo Investigator (v.3.16, MicrobrightField, Inc.).

The publication costs of this article were defrayed in part by payment of page charges. This article must therefore be hereby marked "advertisement" in accordance with 18 USC section 1734 solely to indicate this fact.

\section{REFERENCES}

Amaral, D.G., Price, J.L., Pitkänen, A., and Carmichael, S.T. 1992.

Anatomical organization of the primate amygdaloid complex. In The Amygdala: Neurobiological Aspects of Emotion, Memory, and Mental Dysfunction (ed. J.P. Aggleton). Wiley-Liss, New York.

Amorapanth, P., LeDoux, J.E., and Nader, K. 2000. Different lateral amygdala outputs mediate reactions and actions elicited by a fear-arousing stimulus. Nat. Neurosci. 3: 74-79.

Blanchard, C.D. and Blanchard, R.J. 1972. Innate and conditioned reactions to threat in rats with amygdaloid lesions. J. Comp. Physiol. Psychol. 81: 281-290.

Campeau, S. and Davis, M. 1995. Involvement of the central nucleus and basolateral complex of the amygdala in fear conditioning measured with fear-potentiated startle in rats trained concurrently with auditory and visual conditioned stimuli. J. Neurosci. 15: 2301-2311.

Canteras, N.S. and Swanson, L.W. 1992. Projections of the ventral subiculum to the amygdala, septum, and hypothalamus: A PHAL anterograde tract-tracing study in the rat. J. Comp. Neurol. 324: 180-194.

Davis, M. and Lee, Y. 1998. Fear and anxiety: Possible roles of the amygdala and bed nucleus of the stria terminalis. Cognit.Emot. 12: $277-305$.

Dunn, L.T. and Everitt, B.J. 1988. Double dissociations of the effects of amygdala and insular cortex lesions on conditioned taste aversion, passive avoidance, and neophobia in the rat using the excitotoxin ibotenic acid. Behav. Neurosci. 102: 3-23.

Fendt, M. and Fanselow, M.S. 1999. The neuroanatomical and neurochemical basis of conditioned fear. Neurosci. Biobehav. Rev. 23: 743-760.

Frankland, P.W., Cestari, V., Filipkowski, R.K., McDonald, R.J., and Silva, A.J. 1998. The dorsal hippocampus is essential for context discrimination but not for contextual conditioning. Behav. Neurosci. 112: $863-874$

Helmstetter, F.J. and Bellgowan, P.S. 1994. Effects of muscimol applied to the basolateral amygdala on acquisition and expression of contextual fear conditioning in rats. Behav. Neurosci. 108: 1005-1009.

Hitchcock, J.M. and Davis, M. 1991. Efferent pathway of the amygdala involved in conditioned fear as measured with the fear-potentiated startle paradigm. Behav. Neurosci. 105: 826-842.

Kapp, B.S., Frysinger, R.C., Gallagher, M., and Haselton, J. 1979. Amygdala central nucleus lesions: effect on heart rate conditioning in the rabbit. Physiol. Behav. 23: 1109-1117.

Killcross, S., Robbins, T.W., and Everitt, B.J. 1997. Different types of fear-conditioned behavior mediated by separate nuclei within amygdala. Nature 388: 377-380.

Kim, J.J., Rison, R.A., and Fanselow, M.S. 1993. Effects of amygdala, hippocampus, and periaqueductal gray lesions on short- and long-term contextual fear. Behav. Neurosci. 107: 1-6.

LeDoux, J.E. 2000. Emotion circuits in the brain. Annu. Rev. Neurosci. 23: 155-184.

LeDoux, J.E., Morrison, S.F., and Reis, D.J. 1986. The geniculo-amygdala projection: Electrophysiological characteristics of cells in a fear conditioning pathway. Soc. Neurosci. Abstr. 12: 748.

LeDoux, J.E., Iwata, J., Cicchetti, P., and Reis, D.J. 1988. Different projections of the central amygdaloid nucleus mediate autonomic and behavioral correlates of conditioned fear. J. Neurosci. 8: 2517-2529.

LeDoux, J.E., Cicchetti, P., Xagoraris, A., and Romanski, L.M. 1990a. The lateral amygdaloid nucleus: Sensory interface of the amygdala in fear conditioning. J. Neurosci. 10: 1062-1069.

LeDoux, J.E., Farb, C.F., and Ruggiero, D.A. 1990b. Topographic organization of neurons in the acoustic thalamus that project to the amygdala. J. Neurosci. 10: 1043-1054.

Maisonnette, S.S., Kawasaki, M.C., Coimbra, N.C., and Brandao, M.L. 1996. Effects of lesions of amygdaloid nuclei and substantia nigra on aversive responses induced by electrical stimulation of the inferior colliculus. Brain Res. Bull. 40: 93-98.

Maren, S. and Fanselow, M.S. 1996. The amygdala and fear conditioning: Has the nut been cracked? Neuron 16: 237-240.

Maren, S., ,Aharonov, G., and Fanselow, M.S. 1996. Retrograde Abolition of Conditional Fear After Excitotoxic Lesions in the Basolateral Amygdala of Rats. Behav. Neurosci. 110: 718-726.

. 1997. Neurotoxic lesions of the dorsal hippocampus and Pavlovian fear conditioning in rats. Behav. Brain Res. 88: 261-274. McAllister, W.R. and McAllister, D.E. 1971. Behavioral measurement of

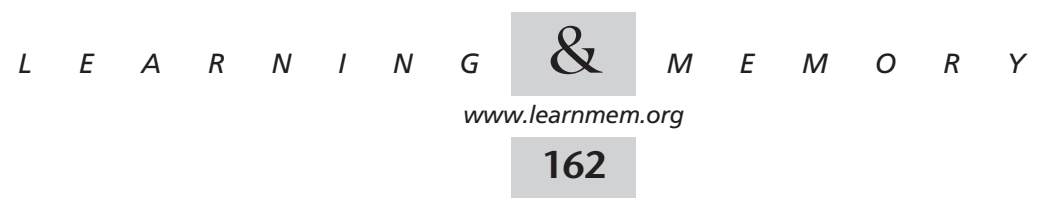


conditioned fear. In Aversive Conditioning and Learning (ed. F.R. Brush), Academic Press, New York.

McDonald, A.J. 1998. Cortical pathways to the mammalian amygdala. Prog. Neurobiol. 55: 257-332.

Miller, N.E. 1948. Studies of fear as an acquirable drive: I. Fear as motivation and fear reduction as reinforcement in the learning of new responses. J. Exp. Psychol. 38: 89-101.

Morgan, M.A., Romanski, L.M., and LeDoux, J.E. 1993. Extinction of emotional learning: contribution of medial prefrontal cortex. Neurosci. Let. 163: 109-113.

Mowrer, O.H. and Lamoreaux, R.R. 1946. Fear as an intervening variable in avoidance conditioning. J. Comp. Psychol. 39: 29-50.

Muller, J., Corodimas, K.P., Fridel, Z., and LeDoux, J.E. 1997. Functional inactivation of the lateral and basal nuclei of the amygdala by muscimol infusion prevents fear conditioning to an explicit CS and to contextual stimuli. Behav. Neurosci. 111: 683-691.

Oakes, M.E. and Coover, G.D. 1997. Effects of small amygdala lesions on fear, but not aggression, in the rat. Physiol. Behav. 61: 45-55.

Paré, D., Smith, Y., and Pare, J.F. 1995. Intra-amygdaloid projections of the basolateral and basomedial nuclei in the cat: Phaseolus vulgaris-leucoagglutinin anterograde tracing at the light and electron microscopic level. Neuroscience 69: 567-583.

Paxinos, G. and Watson, C. 1997. In The Rat Brain in Stereotaxic Coordinates. Academic Press, Sydney.

Phillips, R.G. and LeDoux, J.E. 1992. Differential contribution of amygdala and hippocampus to cued and contextual fear conditioning. Behav. Neurosci. 106: 274-285.

Pitkänen, A., Savander, V., and LeDoux, J.L. 1997. Organization of intra-amygdaloid circuitries: An emerging framework for understanding functions of the amygdala. Trends Neurosci. 20: 517-523.

Poremba, A. and Gabriel, M. 1997. Amygdalar lesions block discriminative avoidance learning and cingulothalamic training-induced neuronal plasticity in rabbits. J. Neurosci. 17: 5237-5244.
Roozendaal, B., Koolhaas, J.M., and Bohus, B. 1991a. Central amygdala lesions affect behavioral and autonomic balance during stress in rats. Physiol. Behav. 50: 777-781.

- 1991b. Central amygdala lesions affect behavioral and autonomic balance during stress in rats. Physiol. Behav. 50: 777-781.

Rosen, J.B., Hitchcock, J.M., Sananes, C.B., Miserendino, M.J., and Davis, M. 1991. A direct projection from the central nucleus of the amygdala to the acoustic startle pathway: Anterograde and retrograde tracing studies. Behav. Neurosci. 105: 817-825.

Sananes, C.B. and Davis, M. 1992. N-methyl-D-aspartate lesions of the lateral and basolateral nuclei of the amygdala block fear-potentiated startle and shock sensitization of startle. Behav. Neurosci. 106: 72-80.

Stefanacci, L., Suzuki, W.A., and Amaral, D.G. 1996. Organization of connections between the amygdaloid complex and the perirhinal and parahippocampal cortices in macaque monkeys. J. Comp. Neurol. 375: 552-582

Walker, D.L. and Davis, M. 1997. Double dissociation between the involvement of the bed nucleus of the stria terminalis and the central nucleus of the amygdala in startle increases produced by conditioned versus unconditioned fear. J. Neurosci. 17: 9375-9383.

Wallace, K.J. and Rosen, J.B. 1999. Lesions of the lateral nucleus of the amygdala decrease freezing in rats to contextual fear conditioning and to a predator. Soc. Neurosci. Abstr. 25: 1618.

Wilensky, A.E., Schafe, G.E., and LeDoux, J.E. 2000. The amygdala modulates memory consolidation of fear-motivated inhibitory avoidance learning but not classical fear conditioning. J. Neurosci. 20: 7059-7066.

Received November 29, 2000; accepted in revised form April 16, 2001

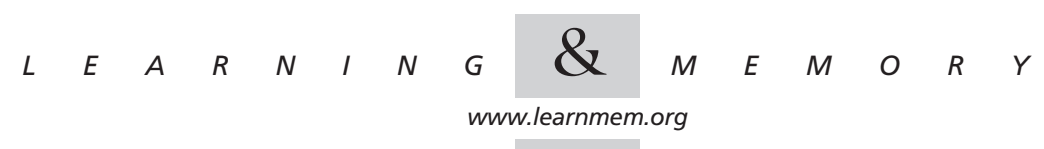




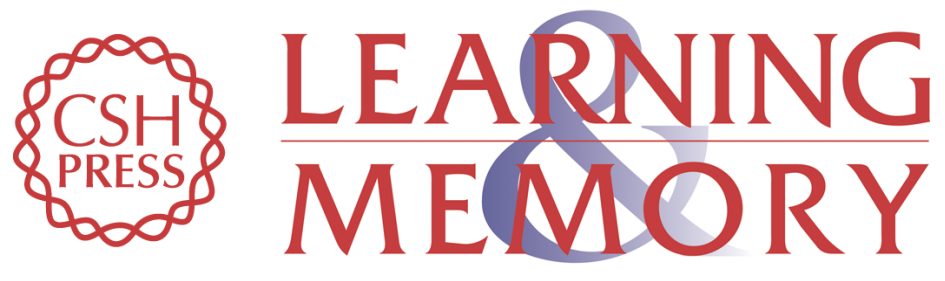

\section{Damage to the Lateral and Central, but Not Other, Amygdaloid Nuclei Prevents the Acquisition of Auditory Fear Conditioning}

Karim Nader, Pedram Majidishad, Prin Amorapanth, et al.

Learn. Mem. 2001, 8:

Access the most recent version at doi:10.1101//m.38101

References This article cites 38 articles, 7 of which can be accessed free at: http://learnmem.cshlp.org/content/8/3/156.full.html\#ref-list-1

License

Email Alerting Receive free email alerts when new articles cite this article - sign up in the box at the Service top right corner of the article or click here. 